\title{
Enhancing implementation research within Canada's investments in the health of women and children globally
}

\author{
Renee Sharma MSc, Helen Scott PhD, Zulfiqar A. Bhutta MBBS PhD
}

— Cite as: CMAJ 2017 March 6;189:E332-3. doi: 10.1503/cmaj.161093

$\mathbf{F}$ ew issues have received as much global attention in recent years as maternal, newborn and child health and survival, a cornerstone of the United Nations' Millennium Development Goals.

Recent research has focused on defining and developing a range of evidence-based interventions across the continuum of care for maternal, newborn and child health; as a result of the implementation of many of these initiatives, global maternal and child mortality fell from about 13 million deaths in 1990 to just over 6 million in 2015. ${ }^{1}$ Yet, progress has been uneven. Disparities between countries, as well as between populations within countries, are evident. These gaps in coverage of essential interventions are related to marginalization of some groups, social inequities and geographic issues. ${ }^{1}$

There has been comparatively little research on strategies to reach those in greatest need. We need to move from "what" to "how best" to package and scale up interventions to address maternal, newborn and child health, and to integrate these within existing programs, which remains a global challenge. ${ }^{1}$ If we are to achieve high, sustainable and equitable coverage of life-saving interventions, addressing this gap with good implementation research is essential, and Canada must contribute to such efforts.

The relatively new field of implementation science refers to "the study of methods to promote the integration of research findings and evidence into healthcare policy and practice," i.e., exploring the ways in which key players influence and interact with the uptake, adoption and implementation of evidence-based interventions, to try to improve delivery and scale up of interventions in specific local contexts. ${ }^{2}$ Related to this is the concept of implementation research, which was defined by Peters and colleagues as the "scientific inquiry into questions concerning implementation - the act of carrying an intention into effect, which in health research can be policies, programmes, or individual practices (collectively called interventions)." 3 The intent of implementation science and related research is to investigate and address major bottlenecks that impede effective implementation of interventions, to test new approaches to improve health programming and to determine a causal relationship between interventions and their impact. ${ }^{4}$ There are few systematic exercises exploring

\section{KEY POINTS}

- Limited research is available on packaging and scaling up interventions to best address global maternal, newborn, child and adolescent health, and their integration within existing programs.

- Good implementation research is essential to achieving high-level, sustainable and equitable coverage of life-saving interventions. Canada must contribute to these research efforts and undertake a review of investments in implementation research within the Muskoka Initiative to date and opportunities moving forward.

- Key areas for implementation research may include developing, deploying and retaining adequate and well-trained human resources; overcoming barriers to intervention access and uptake through community-based strategies and delivery platforms; improving detection and care seeking for childhood illnesses; improving quality of care and monitoring and evaluation; and identifying cost-effective approaches for scale up services.

the relationship of implementation research to major global priorities, and they are limited to specific areas such as the health care work force, ${ }^{5}$ community drivers of intervention uptake ${ }^{6}$ and demand-side financing. ${ }^{7}$ However, an increasing number of exercises are focused on specific implementation questions within countries or programs, ${ }^{8,9}$ in an attempt to strengthen implementation of evidence-based strategies.

Global gains in the health of women and children were made possible by concerted investments and efforts by many national governments, including Canada's, as well as other global organizations offering development assistance, with almost 19\% of development assistance targeting maternal, newborn and child health in $2015 .{ }^{10}$ Many of these investments are focused on evidencebased strategies and essential interventions. However, mere consensus on evidence-based interventions and action plans is insufficient to influence policies or, more importantly, for tangible impact on the ground, unless it is accompanied by robust implementation that is guided by sound and relevant research.

Canada's funding of interventions to improve maternal, newborn and child health through the $\$ 6.35$ billion Muskoka Initiative on Maternal, Newborn and Under-Five Child Health, over the last 
five years ${ }^{11}$ has been criticized for missing opportunities to invest in reproductive health and family planning. It is also unclear if the investments made across a range of approaches to maternal, newborn and child health had a substantial impact on the outcomes related to Millennium Development Goals 4 and 5, and the exact proportion of overall funding for health systems, implementation research and accountability. ${ }^{12}$

A recently undertaken multistakeholder review of Canada's investments in maternal, newborn and child health, and public consultations represent a unique opportunity to assess the impact and relevance of appropriate research to address implementation and impact. The review should consider priorities for Canadian investments in the health of women and children, and target strategies for scaling up and enhancing the effectiveness of key interventions in at-risk populations. Interventions and innovations to improve the health of marginalized populations at risk, those living in fragile states and active conflict zones, and displaced populations should be key priorities.

Given the range of possibilities for research and investment in the health of women and children, some focus and prioritization is needed. Which interventions should be targeted for implementation research and scale up? We suggest a multistep process that starts with an evaluation of the allocations of existing funding to health research, especially implementation research. This evaluation should be followed by consultations with funding bodies and country stakeholders to identify core priorities in the face of finite resources for implementation and research.

Notwithstanding the previous statements, some generalizations can be made about current areas of focus in implementation research. A focus on development, deployment and retention of adequate and well-trained human resources is key to reaching populations who are at risk. Of these, the major opportunity of reducing inequities might relate to working with community strategies and delivery platforms such as community support groups, health care workers and innovations that facilitate delivery of quality services. Major barriers to care seeking and impact also relate to poor quality of services in most midlevel referral health facilities. ${ }^{13}$ Strategies for improving quality of care, incentivizing care seeking, and using technology for monitoring and evaluation in such settings must be prioritized for research.

Because of finite resources and the need to set priorities, research into cost-effective approaches for scale up must receive attention. A Canadian strategy for investment in the Sustainable Development Goals for improved health of women and children that is guided by the best research for prioritizing implementation at scale will likely ensure impact, value for money and enhancement in global knowledge for reaching every woman and every child.

\section{References}

1. A decade of tracking progress for maternal, newborn and child survival: the 2015 Report. Geneva: World Health Organization; 2015. Available: www. countdown2015mnch.org/documents/2015Report/Countdown_to_2015-A_ Decade_of_Tracking_Progress_for_Maternal_Newborn_and_Child_Survival -The2015Report-Conference_Draft.pdf (accessed 2016 July 18).

2. Implementation science information and resources. Bethesda (MD): Fogarty International Center. Available: https://www.fic.nih.gov/researchtopics/pages/ implementationscience.aspx (accessed 2016 Sept 12).

3. Peters DH, Adam T, Alonge O, et al. Implementation research: what it is and how to do it. BMJ 2013;347:f6753.

4. Fixsen DL, Naoom SF, Blase KA, et al. Implementation research: a synthesis of the literature. Tampa (FL): University of South Florida, Louis de la Parte Florida Mental Health Institute, The National Implementation Research Network; 2005. FMHI Publication no. 231. Available: http://ctndisseminationlibrary.org/ PDF/nirnmonograph.pdf (accessed 2016 Sept. 12).

5. Trivedi D. Cochrane review summary: barriers and facilitators to the implementation of lay health worker programmes to improve access to maternal and child health: qualitative evidence synthesis. Prim Health Care Res Dev 2015;16:326-8.

6. Lassi ZS, Bhutta ZA. Community-based intervention packages for reducing maternal and neonatal morbidity and mortality and improving neonatal outcomes. Cochrane Database Syst Rev 2015;(3):CD007754.

7. Murray SF, Hunter BM, Bisht R, et al. Effects of demand-side financing on utilisation, experiences and outcomes of maternity care in low- and middleincome countries: a systematic review. BMC Pregnancy Childbirth 2014;14:30.

8. Uneke CJ, Sombie I, Keita N, et al. An assessment of maternal, newborn and child health implementation studies in Nigeria: implications for evidence informed policymaking and practice. Health Promot Perspect 2016;6:119-27.

9. Goyet S, Touch S, Ir P, et al. Gaps between research and public health priorities in low income countries: evidence from a systematic literature review focused on Cambodia. Implement Sci 2015;10:32.

10. Dieleman JL, Schneider MT, Haakenstad A, et al. Development assistance for health: past trends, associations, and the future of international financial flows for health. Lancet 2016;387:2536-44.

11. Greenhill R, Wadhera C. 10 reasons to applaud Canada's renewed commitment to reproductive health. OpenCanada; 2016. Available: https://www.opencanada .org/features/10-reasons-applaud-canadas-renewed-commitment-reproductive -health/ (accessed 2016 July 18).

12. Kirton J, Kulik J, Bracht C. The political process in global health and nutrition governance: the G8's 2010 Muskoka Initiative on Maternal, Child, and Newborn Health. Ann N Y Acad Sci 2014;1331:186-200.

13. Kruk ME, Leslie HH, Verguet $\mathrm{S}$, et al. Quality of basic maternal care functions in health facilities of five African countries: an analysis of national health system surveys. Lancet Glob Health 2016;4:e845-55.

\section{Competing interests: None declared.}

Affiliations: Centre for Global Child Health (Sharma, Bhutta), The Hospital for Sick Children, Toronto, Ont.; Canadian Partnership for Women and Children's Health (Scott), Ottawa, Ont.

Contributors: Zulfiqar Bhutta wrote the initial draft, with substantial input from Renee Sharma and further comments from Helen Scott. All of the authors revised the manuscript critically for intellectual content, approved the final version to be published and agreed to be accountable for all aspects of the work.
Funding: The Centre for Global Child Health at The Hospital for Sick Children, Toronto, received funding from the Canadian Partnership for Women and Children's Health to conduct the research prioritization exercise and prepare a final report.

This article has been peer reviewed.

Correspondence to: Zulfiqar Bhutta, zulfiqar.bhutta@sickkids.ca 